\title{
Sudden Cardiovascular Death-Presentation of a Case
}

\section{Claribel Plain Pazos ${ }^{1 *}$, Anel Pérez de Alejo Alemán ${ }^{2}$, Carmen Rosa Carmona Pentón ${ }^{1}$, Anisbel Pérez de Alejo Plain ${ }^{3}$, Lázaro Roque Pérez ${ }^{4}$, Leonardo Domínguez Plain ${ }^{5}$,Ginet García Cogler}

${ }^{1}$ Specialist of II Degree in Comprehensive General Medicine, Assistant Professor, Medical Sciences Branch "Lidia Doce Sánchez", Sagua la Grande, Villa Clara, Cuba. ${ }^{2}$ Specialist of I Degree in Internal Medicine, Assistant Professor, Teaching General Teaching Hospital "Mártires del 9 de Abril", Sagua la Grande,Villa Clara, Cuba. ${ }^{3} 2$ th Year Student of Medicine, Medical Sciences Branch “Lidia Doce Sánchez", Sagua la Grande, Villa Clara, Cuba. ${ }^{4} 4$ th Year Student of Medicine, Medical Sciences Branch “Lidia Doce Sánchez", Sagua la Grande, Villa Clara, Cuba. ${ }^{5} 1$ st Year Orthopedics Resident, Clinical Surgical Teaching Hospital “Mártires del 9 de abril”, Sagua la Grande, Villa Clara, Cuba. ${ }^{6}$ Degree in cytohistopathology, Instructor teacher, Medical Sciences Branch "Lidia Doce Sánchez", Sagua la Grande, Villa Clara, Cuba. claribelpp@infomed.sld.cu

*Corresponding Author: Claribel Plain Pazos, Specialist of II Degree in Integral General Medicine, Assistant Professor, Branch of Medical Sciences “Lidia Doce Sánchez", Sagua la Grande, Villa Clara, Cuba.

Abstract

Sudden death is probably the most important challenge of modern cardiology. Not only because of the large number of deaths it causes, but also because of the social impact it causes. It is currently a major public health problem worldwide. The objective of this study is to present a near-clinic of sudden death in a 14-yearold female patient with a history of hypertrophic cardiomyopathy and corset use due to scoliosis who was brought to the emergency room after having suffered a sudden loss of consciousness. In the emergency room, cardiorespiratory arrest is diagnosed and cardiopulmonary resuscitation is performed immediately, not recovering the patient. The enormous challenge posed by the SDC in this century, justified by an increase in the incidence and prevalence of cardiovascular diseases in the coming decades worldwide, makes it necessary to review the current approaches in its approach.

Keywords: sudden death, hypertrophic cardiomyopathy, cardiorespiratory arrest.

\section{INTRODUCTION}

Sudden death (SD) has been spoken for more than 4000 years, in ancient Egypt this death was correlated with symptoms attributable to myocardial ischemia. [1]

Cardiac SD (CSD) is characterized by a collapse or sudden cardiac arrest secondary to cardiac arrhythmias, in people with or without cardiac disease; the blood stops flowing to the brain and the whole organism and causes death if it is not treated within minutes. Some of these patients may have symptom SD shortly before the event, but to establish the definitive diagnosis of an episode of sudden death requires that the symptoms be less than one hour in duration. [1-3] Thus, the three fundamental elements The definition of sudden death is that which is a natural, rapid and unexpected death. [4] Most cases are secondary to ischemic heart disease and occur at the extrahospital level. [2]

$\mathrm{SD}$ is probably the most important challenge in modern cardiology. [1] Not only because of the large number of deaths that it causes, since it represents half of cardiovascular deaths and $25 \%$ of total deaths in adults, but also for the social impact it causes. It is currently an important public health problem worldwide. [1,5-6] This is understandable if we consider that there are between 4 and 5 million annual events in the world, which translates into 10 events per minute. [3] In the West alone, between 450,000 and 500,000 deaths are reported each year, which represents approximately one event per minute. [1,5-6]La incidencia de SD aumenta de form a gradual pero significativa a partir de los 35-40 años y es entre dos y cuatro veces más frecuente en la población masculina.[1] 
$80 \%$ of SDCs occur in the context of known coronary heart disease or not. $[1,3,7]$ In most cases, ischemia triggers ventricular tachyarrhythmia processes that degenerate into ventricular fibrillation (VF), responsible end of the SD. In 15-20\%, structural, congenital or acquired heart disease, [1] such as dilated cardiomyopathy, arrhythmogenic dysplasia of the right ventricle, hypertrophic cardiomyopathy, acquired heart diseases of valvular, coronary or hypertensive origin are responsible. [1,3] In this group, ventricular arrhythmia remains the predominant cause, but bradyarrhythmias also appear as the final cause of SD (blockages, asystole). [1] In a significantly lower percentage, the cause of SDC corresponds to primary electrical phenomena (long QT syndromes, Brugada syndrome, preexcitation syndromes with aberrant conduction, among others). $[1,3]$ VF and ventricular tachycardia (VT) are the arrhythmias responsible for the greatest number of cases of sudden cardiac arrest. Other responsible rhyth SD are asystole and pulseless electrical activity. [2] Cardiopulmonary resuscitation (CPR) prolongs the time window for successful defibrillation. The basic survival chain should be performed before a cardiorespiratory arrest (CA). This chain involves early detection of the patient and activation of the medical emergency system, early CPR, early defibrillation, early advanced care and early post-recovery care. By performing all the links in the survival chain within the first 5 min of the collapse, the survival rates of these patients are significantly improved. [1,2]

The advent of the implantable cardioverterdefibrillator (CVD) represents a great advance in the prevention of SDC, it is a device with a high possibility of reversing a TV or VF episode to sinus rhythm since it can defibrillate any of these arrhythmias in less than 15 seconds. [1-2] VF produces an irregular and chaotic contraction of the ventricular myocardium, with the consequent inability of the heart to maintain body blood flow; if it is not reverted to sinus rhythm, it will go on to asystole and subsequently cause the death of the patient. [2]

Survival of sudden cardiac arrest at the extrahospital level varies widely according to the place of study, but it is estimated to be less than 5\%; In U.S.A. an average survival of $4.6 \%$ has been reported. The major determinant of survival is the performance of early CPR and early defibrillation. [2]

\section{Case Presentation}

Adolescent of 14 years of age, female, Caucasian, with a family history of mother with systemic lupus erythematosus and father with aortic stenosis. Around 9 years old she began to present respiratory distress during physical exertions, she was interconsultated with cardiology who diagnosed hypertrophic cardiomyopathy, she was prescribed treatment with atenolol $25 \mathrm{mg}$ daily until 12 years of age which was replaced by captopril $12.5 \mathrm{mg} 2$ times a day. At 13 years of age, the product of a scoliosis is assessed by Orthopedics, who instructs him to put on a plaster corset and without prior assessment by the cardiologist, with authorization from the mother, this treatment is applied. The patient maintained an active life, with stable hemodynamic function, normal tense and rhythmic heart sounds. Four months before reaching the age of 15 , after climbing a flight of stairs to a second floor, in the school where he studied, he suffers sudden loss of knowledge with a fall to the floor, he is rushed to the nearest medical center where she was diagnosed with cardiorespiratory arrest, her brace was removed and she underwent CPR, she was given Epinephrine and Atropine without answer, declaring herself dead 1 hour later.

Physical Examination upon Arrival at the Polyclinic

(7 minutes after the event) Skin and mucous membranes: pallor, peri-oral and distal cyanosis. Respiratory system: No respiratory movements, no vesicular murmur. Cardiovascular system: Absent cardiac sounds, no presence of pulses. Central Nervous System: Unconscious patient, mydriatic pupils.

\section{Complementary Exams}

Electrocardiogram: Isoelectric line (Asystole).

\section{Necropsy Report}

Direct Cause of Death (DCD): Sudden non-ischemic cardiovascular death in structurally pathological heart. Indirect Cause of Death (CVD): Hypertrophic cardio myopathy.

\section{Discussion}

Hypertrophic cardiomyopathy (HCM) is a genetic heart disease, which is defined as the thickening of the left ventricular wall that is not explained by abnormal load conditions, [8] characterized by its morphological, 
functional, clinical and prognostic heterogeneity. The variable phenotypic expression and its incomplete penetrance have been an obstacle to fully knowing the clinical spectrum and the consequences of the disease. [9] MCH mainly causes mutations in genes that encode sarcomeric contractile proteins. $[9,10]$ In the present case, the patient had no cause to justify hypertrophy and her parents did not suffer from it, so in her case the disease could be related to a genetic mutation.

The majority of those affected by hypertrophic cardiomyopathy are in an asymptomatic phase. The most frequent symptoms are dyspnea on exertion, palpitations, chest pain and syncope. Dyspnea affects more than $50 \%$ of patients at some time during their evolution. Palpitations may be related to atrial arrhythmias and, less frequently, ventricular arrhythmias. Atrial fibrillation (AF) affects $20 \%$ and is usually poorly tolerated. [9] The previously described case was diagnosed fortuitously, as the patient complained of dyspnea on exertion, with no other symptoms suggestive of the disease.

Determining the risk that a patient with hypertrophic cardiomyopathy can suffer from SDCis difficult. Initial studies have shown that adolescents and young adults have an increased risk of SDC. Other recent survival studies show a reduction in risk with increasing the age of affected patients. However, age would not be a major risk factor, being overtaken by others such as non-sustained ventricular tachycardia (NSVT), severe left ventricular hypertrophy and unexplained syncope. [10] In the case presented, the patient was only at risk for age (14 years), had no previous history of ventricular arrhythmia or had suffered syncope, the syncope suffered at the time of death.

In this disease specifically, medical treatment has not shown any protective effect against sudden death, so the implantable cardioverter defibrillator (CVD) is the only therapy considered effective to reduce the risk of sudden death. Patients at higher risk are those who have already presented episodes of sustained ventricular tachycardia or ventricular fibrillation, and for them the implantation of a CVD is indicated as secondary prevention. For the rest of the patients, the decision to implant anCVD is based on the individual estimation of the risk of sudden death. To try to identify patients with higher risk, five clinical criteria have been described, coming from cohort studies, which are considered major risk factors: the presence of unexplained syncope, a history of sudden death in first-degree relatives, thickness ventricular wall $\geq 30$ $\mathrm{mm}$, non-sustained ventricular tachycardia in the Holter study, and abnormal blood pressure response (flat or hypertensive response) in the stress test $[10,11]$. In the case presented, the patient did not have any of these higher risk factors, but although physical effort is not declared as a risk factor to be taken into account as a major criterion, and the patient during her last two years of life maintained her body subjected to a greater physical effort due to the placement of the plaster corset that in addition to supposing an additional load of weight, influenced the respiratory movements by providing a smaller amplitude for the thorax expansibility because the thorax is confined to the plaster frame, to this is added addition that was in a stage of physiological change of the body (puberty) where the energy and metabolic demands are greater, all of which could have influenced the increase from the demand of oxygen to the heart playing a role in the triggering of cellular mechanismSD that could cause some cardiac arrhythmia, perhaps it should have been calculated, jointly with orthopedics with cardiology, the risk / benefit of the placement of the corset before having made the decision, although there is no solid data to support this conclusion, if there are studies that show that some sports can play this role in the unleashing of cellular mechanism SD that lead to arrhythmic events in the presence of a predisposing gene anomaly, $[9,10]$ this being possible also related to the increase in oxygen demand. The implantation of a CVD carries the risk of inappropriate discharges and other complications,[10-12] that is why this preventive therapy should not be considered as a generalized treatment, but should be assessed other criteria in addition to those identified as major criteria when deciding the indications for this treatment.

The causes of SDC described in a patient diagnosed with HCM are spontaneous ventricular fibrillation (VF), asystole, pulseless electrical activity, and complete atrioventricular block. [9] Although in the above-mentioned case the electrocardiogram showed an isoelectric line compatible with asystole, it must be taken into account that its realization was after its arrival in the emergency room of the nearest health entity, where they arrived for 7 minutes after starting the picture, so it cannot be assured that he did not present at first some of these other arrhythmias that could have triggered death. The inability to start CPR early because the patient had a brace that prevented access to the thorax and the absence of a defibrillator at 
the site of the event, negatively affected the recovery of the patient, as it is of vital importance the beginning of CPR in the first minute of the event, in this first minute the chances of success are 90\%, [9] but this possibility drops from $7-10 \%$ per minute without resuscitation and from $3-4 \%$ per minute of resuscitation, so in this patient upon arrival in the emergency room only had a $20 \%$ chance to recover from the PC. It may be necessary to assess the pertinence of having trained personnel to perform CPR in educational centers. In this case it would have been of great help and the possibility of recovery of the elderly patient.

\section{ConCLUSIONS}

$\mathrm{MCH}$ can be the cause of SDC. Ventricular arrhythmias are the main cause of SCD in HCM. The enormous challenge posed by SDC in this century, justified by an increase in the incidence and prevalence of cardiovascular diseases in the coming decades worldwide, makes it necessary to review current approaches in its approach. The identification of risk predictors in susceptible population groups where $90 \%$ of the events are manifested, together with the diagnosis and effective treatment of cardiac arrest, are some of the most important pillars. [3]

\section{REFERENCES}

[1] Fitz Maurice DM, Di Tommaso F, Barros Pertuz MC, Álvarez Mendoza W, Spagnuolo D, Sastre P. Nuevas áreas de vida-Revisión muerte súbita 2018. Revista de la Asociación Médica Argentina 131.3 (2018)

[2] Rodríguez Reyes $H$, Muñoz Gutiérrez M, Márquez Manlio F, Pozas Garza G, Asensio Lafuente E, Ortíz Galván F, et al . Muerte súbita cardiaca. Estratificación de riesgo, prevención y tratamiento. Arch. Cardiol. Méx. 85.4 (2015): 329-336.
[3] Ochoa Montes LA. Muerte súbita cardiovascular: un desafío actual. Rev cubana de Med 56.1 (2017): 1-3

[4] Guindo J. Características de la muerte súbita. Quirón Salud (2016)

[5] Bayés de Luna A, et al. Actualización de la muerte súbita cardíaca: epidemiología y estratificación del riesgo. RevEspMed Legal 44.1 (2017): 5-12

[6] Ochoa LA. Exclusión social y muerte súbita cardíaca. Rev Cubana Salud Pública 36.3 (2010)

[7] JiménezJáimez J, et al. Diagnóstico clínico y genético de la muerte súbita cardiaca de origen no isquémico. Revista Española de Cardiología 70.10 (2017): 808-816

[8] Dávila F, et al. Cardiomiopatía hipertrófica: experiencia de 5 años. Revista Colombiana de Cardiología 24.3 (2017): 297-297.

[9] Pérez Sánchez I, et al. Factores que influyen en la expresión fenotípica de la miocardiopatía hipertrófica en portadores genéticos. Revista Española de Cardiología, 71.3 (2018): 146-154.

[10] EstradaA,etal.Miocardiopatíahipertrófica:¿cómo evaluamos en 2018 el riesgo de muerte súbita?. Revista Uruguaya de Cardiología 33.3 (2018): 252-279.

[11] Sarrias A, et al. Terapia con desfibrilador automático implantable en la miocardiopatía hipertrófica: utilidad en prevención primaria y secundaria. Revista Española de Cardiología 68.6 (2015): 492-496.

[12] Mirelis JG, et al. El volumen extracelular no se asocia a arritmias malignas en miocardiopatía hipertrófica de alto riesgo. Revista Española de Cardiología 70.11 (2017): 933-940.

Citation: Claribel Plain Pazos, Anel Pérez de Alejo Alemán, Carmen Rosa Carmona Pentón, Anisbel Pérez de Alejo Plain, Lázaro Roque Pérez, Leonardo Domínguez Plain,Ginet García Cogler. Sudden Cardiovascular Death-Presentation of a Case. Archives of Emergency Medicine and Intensive Care. 2019; 2(1): 18-21.

Copyright: (C) 2019 Claribel Plain Pazos, Anel Pérez de Alejo Alemán, Carmen Rosa Carmona Pentón, Anisbel Pérez de Alejo Plain, Lázaro Roque Pérez, Leonardo Domínguez Plain,Ginet García Cogler. This is an open access article distributed under the Creative Commons Attribution License, which permits unrestricted use, distribution, and reproduction in any medium, provided the original work is properly cited. 